\title{
Electrochemical Generation of Zn-Chitosan Composite Coating on Mild Steel and its Corrosion Studies
}

\author{
Kanagalasara Vathsala, Thimmappa Venkatarangaiah Venkatesha, Beekanahalli Mokshanatha \\ Praveen, Kudlur Onkarappa Nayana \\ Department of Studies in Chemistry, School of Chemical Sciences, Kuvempu University, Shankaraghatta, India \\ E-mail:drtvvenkatesha@yahoo.co.uk \\ Received December 16, 2009; revised February 26, 2010; accepted March 6, 2010
}

\begin{abstract}
A Zinc-Chitosan composite coating was generated on mild steel from zinc sulphate-sodium chloride electrolyte by electrodeposition. The electrolyte constituents were optimized for good composite coating. The corrosion resistance behavior of the composite was examined by weight loss, polarization and impedance methods using $3.5 \mathrm{wt} \% \mathrm{NaCl}$ neutral solution as medium. Separate polarization profiles were recorded for composite coating and compared with zinc coated sample. SEM images of coatings were recorded for the pure and composite coating.
\end{abstract}

Keywords: Composite coating, Chitosan, SEM, Impedance, Electrodeposition

\section{Introduction}

Zinc electroplating is an industrial process and is widely used to coat on steel for enhancing its service life. As zinc is electrochemically more active than steel and hence it sacrificially protect the steel from corrosion. However zinc itself undergoes corrosion leading to the formation of zinc compounds called white rust on its surface. This tendency of formation of white rust reduces the life of the coating from the expected period. Therefore to enhance the life span of the zinc coating and to avoid the white rust formation the alternative methods like surface modification is adopted. The earlier modification methods are associated with chromate based formulations and the procedure is very simple to generate passive chromate films on corroding zinc coatings. The use of chromate passivation is prohibited because of pollution hazards. An alternate to this chromation is to generate surface films or surface barriers with specific organic molecules or with certain addition agents [1-6]. Also the service life of zinc coating is enhanced by including the inert materials in its coating. The inclusion is done by codeposition of these materials with zinc and thus generating composite coating. These zinc composite coatings exhibit better corrosion resistance property. Nowadays the nanosized materials are codeposited to get better zinc composite with better corrosion resistance [7-10].

A survey of literature reveals that the conducting polymers were used for anticorrosive coatings and as inhibitor for steel [11-13]. However limited information connected to zinc - polymer composite coatings on steel is available in the literature and especially with zinc biopolymer composites.

The chitosan is one such biopolymer used in corrosion inhibition of mild steel without causing environmental problems. Chitosan possess good biocompatibility, chemical resistance, mechanical strength, antimicrobial properties and thermal stability and have been utilized successfully in biotechnology, for different applications. The hydroxyl apatite chitosan nanocomposite was obtained on stainless steel to provide better corrosion protection $[14,15]$. Chitosan is widely used in industry due to its film forming and gelation characteristics. In dilute solutions it is a linear polycation with high charge density. This electrochemical property was utilized in the present work to get the zinc chitosan composite film on mild steel from electrolysis and its corrosion resistance property was tested.

\section{Experimental}

\subsection{Plating Process}

Zinc and Zn-chitosan coatings were electrically deposited from sulphate-chloride bath. The constituents of the bath were $250 \mathrm{~g} / \mathrm{L} \mathrm{ZnSO}_{4} \cdot 7 \mathrm{H}_{2} \mathrm{O}, 40 \mathrm{~g} / \mathrm{L} \mathrm{NaCl}, 30 \mathrm{~g} / \mathrm{L}$ $\mathrm{H}_{3} \mathrm{BO}_{3}$ and $0 . \mathrm{g} / \mathrm{L}$ chitosan ( $88 \%$ deacetylated). In all the 
experiments distilled water and analytical grade reagents were used. The $\mathrm{pH}$ of the bath solution was adjusted to 2.5-3 by adding dil. $\mathrm{H}_{2} \mathrm{SO}_{4}$ and $\mathrm{NaHCO}_{3}$. The bath was stirred for few hours before subjecting it into plating experiments. The cathode was mild steel and anode was zinc $(99.99 \%)$. The mild steel surface was polished mechanically, and degreased with trichloroethylene in degreased plant followed by water wash. Before each experiment the zinc surface was activated by dipping in $10 \% \mathrm{HCl}$ for few seconds and was washed with water. Equal area of anode and cathode was selected for electrode position process. The bath temperature was at 300 $\mathrm{K}$. The deposition process was carried at $4 \mathrm{~A} / \mathrm{dm}^{2}$ and under mechanical stirring.

\subsection{Weight Loss Measurements}

The coating thickness prepared for corrosion tests was in the range of $10-15 \mu \mathrm{m}$. The corrosion rate by weight loss measurements were performed for mild steel samples coated with pure zinc and Zn-chitosan composite. The electrolyte was $3.5 \mathrm{wt} \% \mathrm{NaCl}$ solution and the test samples were immersed vertically in the solution which was maintained at room temperature. The difference in weight was measured once in every 24 hours for a period of 15 days. In each weight loss measurement the corroded samples were rinsed in alcohol, dried with hot air, and then the weight was noted. The weight loss evaluated was used for estimating the corrosion rate.

\subsection{Salt Spray Test}

The salt spray test as per (ASTM B 117) was carried out in a closed chamber. The deposited plates were freely hanged inside the chamber and subjected to continuous spray of neutral $5 \mathrm{wt} \% \mathrm{NaCl}$ vapors. The specimens were observed periodically and the duration of the time for the formation of the white rust was noted.

\subsection{Electrochemical Measurements}

A conventional 3-electrode cell was used for polarization studies. The zinc coated or $\mathrm{Zn}$-chitosan composite coated specimen with surface area of $1 \mathrm{~cm}^{2}$ was used as working electrode. Saturated calomel and platinum foil were employed as reference and counter electrodes respectively. The electrolyte was $3.5 \mathrm{wt} \% \mathrm{NaCl}$ solution. The corrosion resistance property of these specimens was evaluated from the anodic polarization curves.

The electrochemical impedance measurements were performed using AUTOLAB from Eco-chemie made in Netherlands. The steel specimens and their dimensions were same as that of polarization experiment. The EIS was recorded in the frequency range from $100 \mathrm{kHz}$ to 10 $\mathrm{MHz}$ with $\pm 5 \mathrm{mV}$ AC amplitude sine wave generated by a frequency response analyzer.

The surface morphology of the coatings was examined using a JEOL-JEM-1200-EX II scanning electron microscope

\section{Results and Discussion}

\subsection{Corrosion Rate Result}

The zinc and composite coatings was generated on separate mild steel plates having the thickness of about $10-15 \mu \mathrm{m}$. The steel panels were immersed completely in $3.5 \mathrm{wt} \% \mathrm{NaCl}$ solution for different time intervals and the weight loss values were used to calculate the corrosion rate. Figure 1 represents the corrosion rate (wt loss/ hour) profiles with respect to number of hours. The corrosion rates of both composite and zinc coatings were very high in the beginning and decrease exponentially in the middle and it becomes constant after 200 and $150 \mathrm{hrs}$ for zinc and composite coatings respectively. At any given time the rate of corrosion for composite was always less than that of zinc coating. This suggests that the composite coating possess higher corrosion resistance property. This property was due to the presence of chitosan in the zinc matrix.

\subsection{Salt Spray Test Result}

The industrial method of testing the corrosion behavior of zinc-plated objects is salt spray test. The test was conducted by spraying $5 \mathrm{wt} \% \mathrm{NaCl}$ solution in a chamber. The $\mathrm{NaCl}$ drops accumulated on the surface of the coated specimens facilitate the corrosion resulting in zinc salts called white rust. The time taken for the formation of white rust was the indication of the corrosion rate. The higher corrosion resistance delays the production of white rust. In the present case the pure zinc produced the white rust after $19 \mathrm{hrs}$ and the Zn-chitosan composite

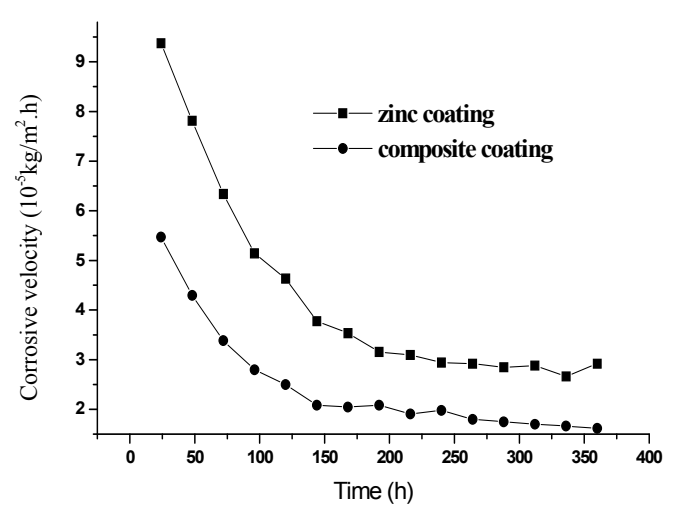

Figure 1. Variation of the corrosion rate with immersion time for zinc and composite coated samples in $3.5 \mathrm{wt} \%$ NaCl solution. 
produced the white rust after $28 \mathrm{hrs}$. This test confirms the enhancement of corrosion resistance of zinc in the presence of chitosan in its matrix.

\subsection{Electrochemical Result}

Figure 2 shows anodic polarization profile of zinc and $\mathrm{Zn}$-chitosan coated sample in $3.5 \mathrm{wt} \% \mathrm{NaCl}$ solution. The linear variation was observed in the beginning up to $-1.01 \mathrm{~V}$ and afterwards there was gradual increase in current indicating electrochemical oxidation of zinc. However in the case of composite coating, the potential was always more positive for any given current density. This indicates that the composite requires extra potential to bring anodic reaction. Thus the composite possess higher resistance to corrosion process on its surface.

The Nyquist plots for zinc and $\mathrm{Zn}$-chitosan coatings are shown in Figure 3. The larger loop was produced by Zn-chitosan coatings whereas smaller semicircle was obtained for pure zinc. It can be easily observed from the figure that $\mathrm{Rp}$ values are higher for composite coating than zinc coating. This indicates that composite coating is more corrosion resistant than zinc coating.

\subsection{Surface morphology}

The SEM images at lower and higher magnification were represented in Figure 4. Also the SEM images of corroded surface of zinc and composite are given in Figure 5 and Figure 6. The SEM images show the practical evidences on the corrosion protection ability of composite coating.

\section{Discussion.}

The experimental results of the present investigations inferred that the chitosan can be included in the deposit easily. It acquires a positive charge by protonation in

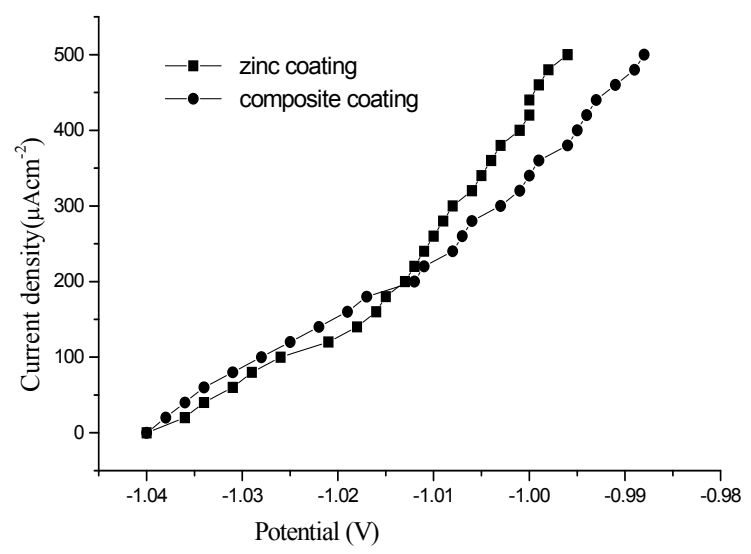

Figure 2. Anode polarization curves for zinc and composite coated samples in $3.5 \mathrm{wt}$ \% $\mathrm{NaCl}$ solution.

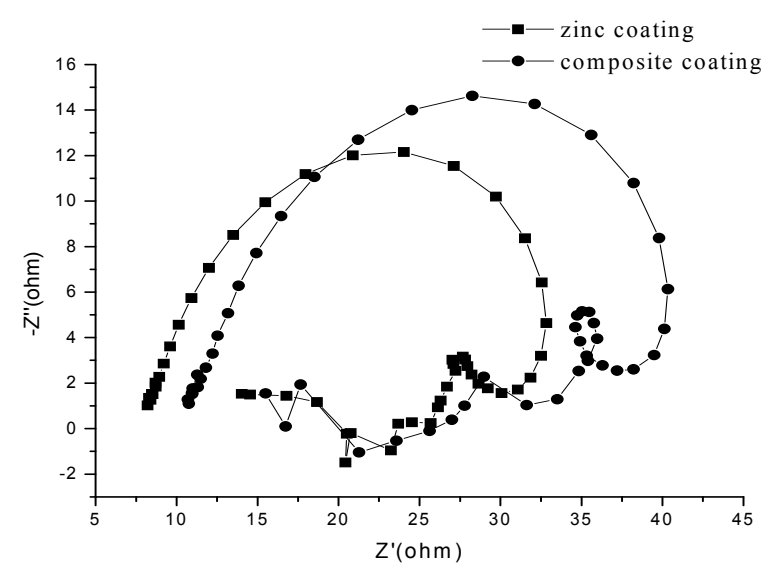

Figure 3. Impedance diagrams for pure zinc coated and $\mathrm{Zn}$-chitosan coated samples in $3.5 \mathrm{wt}$ \% $\mathrm{NaCl}$ solution.
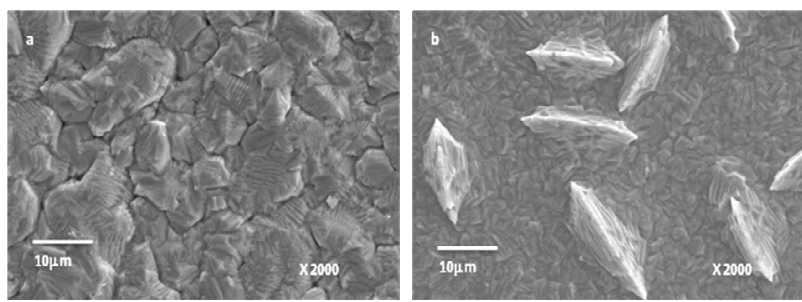

Figure 4. SEM images for the two samples. (a) Zinc coating, (b) composite coating.
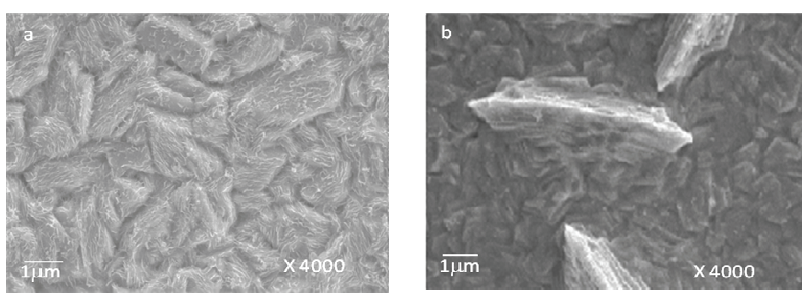

Figure 5. SEM images for two samples after anodic polarization for (a) zinc coated; (b) composite coated sample.
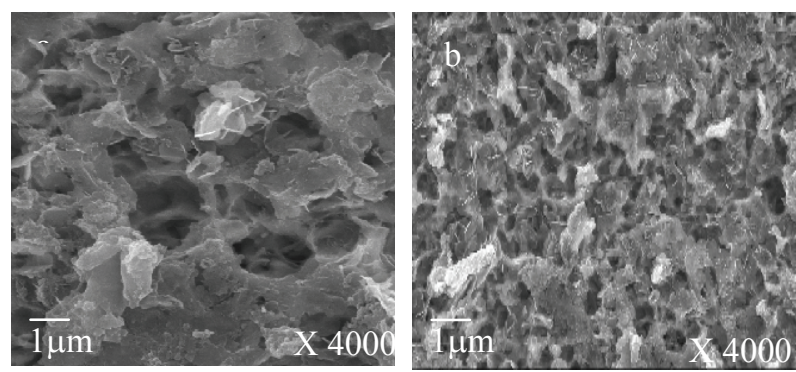

Figure 6. SEM images for two samples after 15 day's weight loss measurements. (a) zinc coated; (b) composite coated.

Acid solution [15].

$$
\text { chit }-\mathrm{NH}_{2}+\mathrm{H}_{3} \mathrm{O}^{+} \rightarrow \text { chit }-\mathrm{NH}_{3}^{+}+\mathrm{H}_{2} \mathrm{O}
$$

During electrodeposition naturally $\mathrm{H}_{2}$ evolution takes place and there is increase in $\mathrm{OH}^{-}$ions at the close vi- 
cinity of the cathode. These $\mathrm{OH}^{-}$ions combine with proton of the protonated chitosan at the electrode and get precipitated. This solid precipitate codeposited with the zinc. Generally the composite coating of zinc with other material is generated by dispersing the insoluble particles in the electrolyte. Here the solid is dispersed in liquid state. Even the same procedure is followed in polymermetal composite. However in chitosan-metal composite, the chitosan was codeposited from electrolyte, where in chitosan and electrolyte were in single phase. Chitosan exists as polycation in acid solution and reaches the cathode easily during electrodeposition and it will get deposited on the cathodic site.

The results of corrosion rates for zinc and composite coatings from chemical and electrochemical methods are in agreement with each other. The composite coating with chitosan provides higher corrosion resistance than zinc coating. As these molecules possess higher molecular weight and larger molecular size, they cover the corroding surface to larger extent through its cationic point attached to cathodic site of the surface. Thus there may be formation of barrier which prevents the direct contact of corroding metal with the corrosive medium. There are reports in the literature on the corrosion inhibition of polymer molecule to metals [16-17]. The weight loss method, impedance, salt spray test results of the present study revealed higher corrosion resistance property of composite coating. In all these methods, probably chitosan hinders the anodic reaction and finally the corrosion rate was decreased. The delayed white rust formation in salt spray inferred that the inclusion of the chitosan makes the composite coating to acquire more corrosion resistant property. Also the higher $\mathrm{R}_{\mathrm{P}}$ value and more positive potential of composite coating make the deposit nobler than zinc coating. The corrosion rate and time profiles indicate that the corrosion velocity (Figure 1) of composite was always less than zinc coating.

Figure 4 shows the SEM image of the zinc and Znchitosan composite coatings. Composite coated samples have a ridge shaped grains on the surface which reveals the inclusion of chitosan into zinc matrix.

The anodic polarization of zinc and composite (Figure 5(a) and 5(b) showed that zinc coating undergoes more dissolution than composite. The crystals get dissolved easily during corrosion (Figure 5(a)). This had not been observed in composite coating (Figure 5(b)). The SEM images of samples after 15 days of chemical corrosion showed larger deep pits arising out of higher corrosion rate for zinc coating (Figure 6(a)). The composite coating (Figure 6(b)) exhibited small pits which distributed throughout the surface and resulted uniform corrosion with lower rate. These experimental results revealed higher corrosion resistance property of Zn-chitosan composite coating compared to pure zinc coating.

\section{Conclusions}

Zn-chitosan composite was generated by electrodeposition from sulphate bath. The precipitated chitosan was codeposited along with zinc. The performance of composite coating was established from the results of weight loss, polarization, impedance and salt spray test. In all these studies Zn-chitosan composite exhibits better anti corrosion performance. The SEM images of surface provide an evidence for the presence of chitosan in coating and crystalline nature. The composite showed uniform and lower corrosion rates than that of zinc coating.

\section{Acknowledgements}

The authors are grateful to University Grant Commission, New Delhi, Govt. of India [Major Research Project F.32-220/2006(SR)] for providing financial assistance.

\section{References}

[1] K. L. Lin, C. F. Yang and J. T. Lee, "Growth Behavior and Corrosion Resistance of 5\% Al-Zn Coating," Corrosion, Vol. 49, No. 9, 1993, pp. 9-12.

[2] G. Barcelo, M. Sarret, C. Müller and J. Pregonas. "Corrosion Resistance and Mechanical Properties of Zinc Electrocoatings," Electrochimical Acta, Vol. 43, No. 1-2, 1998, pp. 13-20.

[3] A. Y. Hosny, M. E. El-Rafei, T. A. Ramadan, B. A. El-Gafari and S. M. Morsy, "Corrosion Resistance of Zinc Coatings Produced from a Sulfate Bath," Metal Finishing, Vol. 93, No. 11, 1995, pp. 55-59.

[4] B. Bozzini, V. Accardi, P. L. Cavallotti and F. Pavan, "Electrodeposition and Plastic Behavior of Low-Manganese Zinc-Manganese Alloy Coatings for Automotive Applications," Metal Finishing, Vol. 97, No. 5, 1999, p. 33.

[5] C. Müller, M. Sarret, E. Garcia and J. A. Ortega, "CrFree Passivation on ZnNi Alloys," Journal of the Electrochemical Society, Vol. 151, No. 2, 2004, pp. C149C154.

[6] S. Tamil Selvi, V. Raman and N. Rajendran, "Corrosion Inhibition of Mild Steel by Benzotriazole Derivatives in Acidic Medium," Journal of Applied Electrochemistry, Vol. 33, No. 12, 2003, pp. 1175-1182.

[7] B. M. Praveen, T. V. Venkatesha, Y. A. Naik, and K. Prashantha, "Corrosion Studies of Carbon Nanotubes-Zn Composite Coating," Surface and Coating Technology, Vol. 201, No. 12, 2007, pp. 5836-5842.

[8] B. M. Praveen, T. V. Venkatesha and Y. A. Naik, "Corrosion Behaviour of $\mathrm{Zn}-\mathrm{TiO}_{2}$ Composite Coating," Synthesis and Reactivity in Inorganic, Metal-Organic and Nano-Metal Chemistry, Vol. 37, No. 6, 2007, pp. 461465.

[9] J. Li, J. Jiang, H. He, and Y. Sun, "Synthesis, Microstructure, and Mechanical Properties of $\mathrm{Tio}_{2} / \mathrm{Ni}$ Nanocomposite Coatings," Journal of Materials Science Letters, Vol. 21, No. 12, 2002, pp. 939-941. 
[10] Macro Musiani, "Electrodeposition of Composites: An Expanding Subject in Electrochemical Materials Science," Electrochimica Acta, Vol. 45, No. 20, 2000, pp. 3397-3402.

[11] A. A. Pud, G. S. Shapoval, P. Kamarchik, N. A. Ogurtsov, V. F. Gromovaya, I. E. Myronyuk and Yu. V. Kontsur. "Electrochemical Behavior of Mild Steel Coated by Polyaniline Doped with Organic Sulfonic Acids," Synthetic Metals, Vol. 107, No. 2, 1999, pp. 111-115.

[12] R. C. Patil and S. Radhakrishnan. "Conducting Polymer Based Hybrid Nano-Composites for Enhanced Corrosion Protective Coatings," Progress in Organic Coatings, Vol. 57, No. 4, 2006, pp. 332-336.

[13] B. Szeptycka and A.Gajewska-MidziaIek, "the Influence of the Structure of the Nano-Composite Ni-PTFE Coatings on the Corrosion Properties," Review of Advanced Material Science, Vol. 14, 2007, pp. 135-140.
[14] F. B. Waanders, S. W. Vorster and A. J, Geldenhuys, "Biopolymer Corrosion Inhibition of Mild Steel: Electrochemical/Mössbauer Results," Hyperfine Interactions, Vol. 139-140, No. 1-4, 2002, pp. 133-139.

[15] X. Pang and I. Zhitomirsky, "Electrophoretic Deposition of Composite Hydroxyapatite-Chitosan Coatings," Materials Characterization, Vol. 58, No. 4, 2007, pp. 339-348.

[16] H. P. Sachin, G. Achary, Y. Arthoba Naik and T. V. Venkatesha, "Polynitroaniline as Brightener for ZincNickel Alloy Plating from Non-Cyanide Sulphate Bath," Bulletin of Materials Science, Vol. 30, No. 1, 2007, pp. 57-63.

[17] S. Sathiyanarayanan, S. S. Azim and G. A. Vekatachari, "New Corrosion Protection Coating with Polyaniline- $\mathrm{TiO}_{2}$ Composite for Steel," Electrochimica Acta, Vol. 52, No. 5, 2007, pp. 2068-2074. 